\section{sciendo MATHEMATICAL MODEL FOR PREDICTING THE SHIP SPEED IN THE ACTUAL WEATHER CONDITIONS ON THE PLANNED OCEAN ROUTE}

DOI 10.2478/ntpe-2018-0013

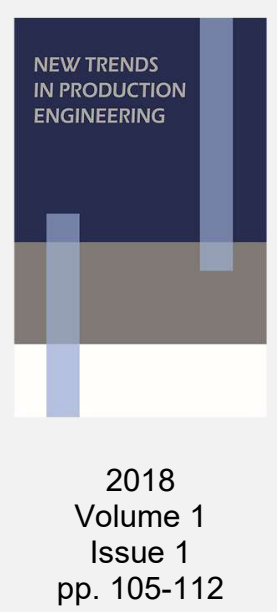

\begin{abstract}
While operating the ship, one of the most important tasks is forecasting the ocean route. The vessel's speed characteristics are used to predict the route. Commonly used are very simplified algorithms for calculating those characteristics in which only a few basic ship parameters are used. The article presents a more detailed mathematical model for forecasting the speed of the ship in real weather conditions. This model requires more detailed geometric data of the ship and its propulsion (propeller and propulsion engine), but this data is available for operating ships.
\end{abstract}

Keywords: ocean route, ship speed, wind, current, wave, ship propulsion

\title{
INTRODUCTION
}

When operating a ship, one of the most important tasks is to forecast the ocean route. When forecasting the ocean route, the most common criteria are (Wiśniewski, 1991):

- minimization of the time voyage,

- minimizing of the fuel consumption,

- minimization of the fuel consumption with the prescribed time voyage.

Regardless of which of these criteria is used, when navigating in particularly difficult weather conditions (storm waves and/or high wind speed, tropical cyclones), the safety of the ship, cargo and crew are also taken into account when forecasting the shipping route.

Forecasting of ocean routes is performed by specialized institutions using appropriate computer systems for this purpose, such as: SPOS (Program SPOS, 2009) (Ship Performance Optimization System), BON VOYAGE (Bon Voyage System, 2016, Szymanski and Wisniewski, 2016). These systems use appropriate weather models, eg ECMWF (The European Centre for Medium - Range Weather Forecasts), UKMO (UK Meteorological Office), NCEP (American National Weather Service) (Wiśniewski et al., 2012) and algorithms for forecasting the shipping route. These algorithms use the speed and fuel characteristics of the ship, depending on the actual weather conditions occurring in the waters through which the shipping route runs.

Vessel speed characteristics for given weather parameters can be calculated:

- from algorithms included in programs for forecasting ocean routes,

- algorithms developed on the basis of statistical analysis of a large number of measurements made on ships sailing on various oceanic routes in various weather conditions (Białostocki and Konovessis, 2016),

- with accurate calculation algorithms verified on the basis of model tests or measurements on the ships.

The algorithms, according to which velocity and fuel characteristics are not published in the mentioned systems (SPOS, BonVoyage), are probably very simple and not very precise, because a very small number of parameters characterizing the ship and the propulsion engine are used for calculations. Calculation of speed and fuel characteristics are performed for the 
ships built, for which there is design documentation, results of experimental model tests, as well as results of trial tests. There is nothing to prevent these algorithms from being more accurate and using a larger number of the ship and propulsion parameters.

The article presents its own mathematical model of calculating the speed of the ship on a given shipping route under given real weather conditions.

\section{IMPACT OF THE MARINE ENVIRONMENT ON A SHIP ON THE NAVIGATION LINE NAVIGATED}

During a cruise in real weather conditions on a given sailing route on the ship, apart from the resistance on calm water, there act additional forces from wind, waves and possibly from surface sea currents, Fig. 1.

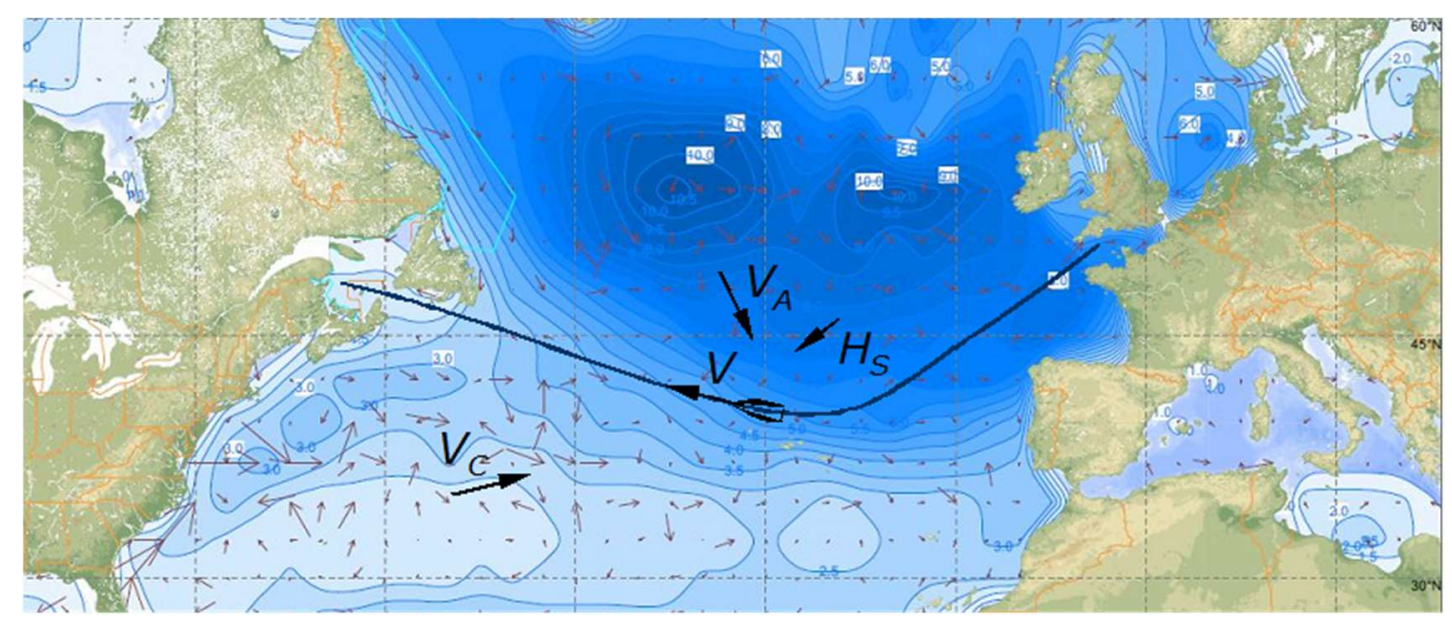

Fig. 1. An example of a shipping route and directions of the impact of the marine environment on the ship ( $V_{A}-$ wind speed, $H_{S}-$ significant height wave, $V_{C}-$ current speed)

The total resistance of the ship in real weather conditions is equal:

$$
R_{T}=R_{V x}+\Delta R
$$

where:

$R_{V x}$ - ship resistance in calm water,

$\Delta R$ - additional resistance of the ship from wind and wave and steering devices:

$$
\Delta R=R_{C x}+R_{A x}+R_{W x}+R_{R x},
$$

$R_{C x}$ - additional resistance from surface currents,

$R_{A x}$ - additional resistance from the wind,

$R_{W x}$ - additional resistance from the waves,

$R_{R x}$ - additional resistance of e.g. steering devices (e.g. rudder fin), that keep vessel on a given course (disturbance of the course are also caused by the impact of wind and wave).

\section{Ship's resistance and additional impacts from surface sea currents}

The impact of surface sea current is the same phenomenon as the ship's resistance on calm $R_{V}$ water. Hence the resultant impact of $R_{C V}$ water and sea current considering the drift angle $\beta$ of the ship can be calculated from the formulas:

where:

$$
\begin{gathered}
R_{C V x}=\frac{1}{2} \rho_{w} S V_{R V}^{2} C_{x}\left(\beta_{R V}\right), \\
R_{C V y}=\frac{1}{2} \rho_{w} S V_{R V}^{2} C_{y}\left(\beta_{R V}\right), \\
M_{C V z}=\frac{1}{2} \rho_{w} S L V_{R V}^{2} C_{m}\left(\beta_{R V}\right),
\end{gathered}
$$

$\rho_{w}$ - water density,

$S$ - lateral projection of underwater ship hull surface onto ship's plane of symmetry PS, 
$L$ - ship length,

$C_{x}, C_{y}, C_{m}$ - coefficients of resistance forces and moment,

$V_{R V}$ - relative speed of water (Fig. 2),

$\beta_{R V}$ - relative drift angle (Fig. 2):

$$
\begin{gathered}
V_{R V}=\sqrt{\left(V_{R V x}\right)^{2}+\left(V_{R V y}\right)^{2}}, \\
\beta_{R V}=\operatorname{arctg} \frac{-V_{R V y}}{V_{R V x}}, \\
V_{R V x}=V_{x}-V_{C} \cos \beta_{C}, \\
V_{R V y}=V_{y}-V_{C} \sin \beta_{C},
\end{gathered}
$$

$V_{x}=V \cos \beta, V_{y}=V \sin \beta-$ absolute speed ship components,

$\beta$ - drift angle at absolute speed,

$V_{C}$ - surface sea current velocity,

$\beta_{C}$ - sea current direction relative to the ship (Fig. 2),

$$
\beta_{C}=\gamma_{C}-\psi \text {, }
$$

$\gamma_{C}$ - geographical direction of surface current, $\left(\gamma_{C}=0^{\circ}\right.$ northbound current, $\gamma_{C}=90^{\circ}$ eastbound current),

$\psi$ - geographical course of ship, ( $\psi=0^{\circ}$ northward course, $\psi=90^{\circ}$ eastward course).

If the sea current velocity $V_{C}=0$ this equation (3) describes the ship's resistance on calm water $R_{V}$. If the drift angle $\beta=0$ then the equation (3) only describes the longitudinal component $R_{V x}$ of the resistance in rectilinear movement.

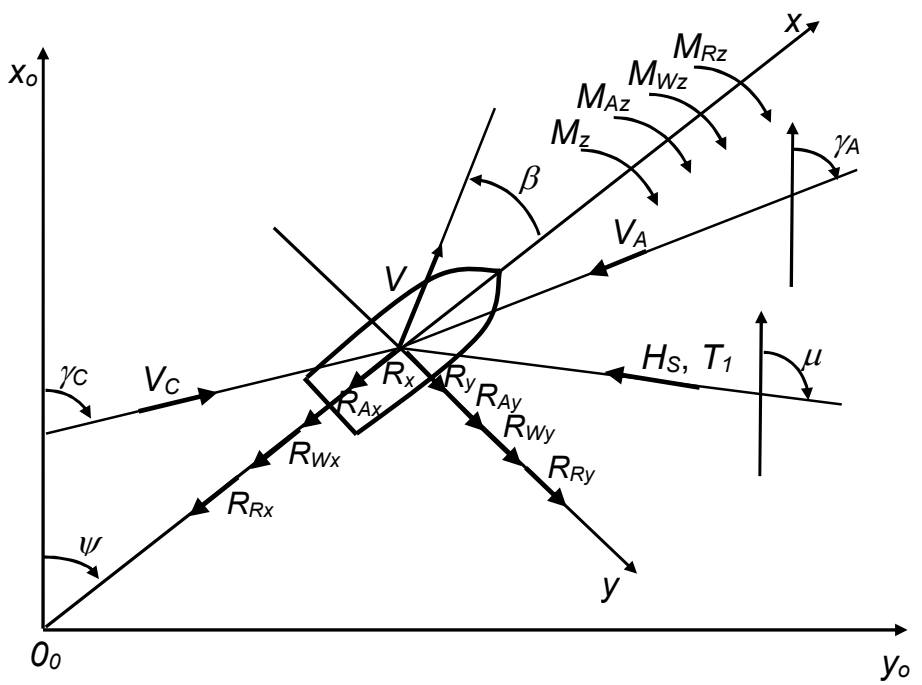

Fig. 2. Parts of the total ship resistance $R_{x} R_{y} M_{z}$ (water, wind, waves), course the of ship and direction of current, wind, waves

\section{Wind influence on the ship}

The mean wind forces acting on the sailing ship can be calculated by using the following formulas:

$$
\begin{aligned}
& R_{A x}=-\frac{1}{2} \rho_{A} S_{x} V_{R A}^{2} C_{A x}\left(\beta_{R A}\right), \\
& R_{A y}=\frac{1}{2} \rho_{A} S_{y} V_{R A}^{2} C_{A y}\left(\beta_{R A}\right), \\
& M_{A z}=\frac{1}{2} \rho_{A} S_{y} L V_{R A}^{2} C_{A m}\left(\beta_{R A}\right),
\end{aligned}
$$

where:

$\rho_{A}$ - air density,

$S_{x}, S_{y}$ - areas of front and side projections of above water part on the ship onto midship and symmetry plane of the ship, respectively,

$L$ - ship length,

$V_{R A}$ - relative wind speed (Fig. 2), 
$C_{A x}, C_{A y}, C_{A m}\left(\beta_{R A}\right)$-aero-dynamical drag coefficients of the above-water part of the ship surface, dependent on the relative wind direction $\left(\beta_{R A}\right)$,

$\beta_{R A}$ - relative wind direction (Fig. 2).

$$
\begin{gathered}
V_{R A}=\sqrt{\left(V_{R A x}\right)^{2}+\left(V_{R A y}\right)^{2}}, \\
V_{R A x}=V_{A} \cos \beta_{A}-V, \\
V_{R A y}=V_{A} \sin \beta_{A}, \\
\beta_{A}=\gamma_{A}-\psi+180^{\circ},
\end{gathered}
$$

$\beta_{A}-$ wind direction relative to the ship $\left(\beta_{A}=0^{\circ}\right.$ wind from the stern of the ship, $\beta_{A}=90^{\circ}$ wind on LB ship),

$$
\beta_{R A}=\operatorname{arctg} \frac{-V_{R A y}}{V_{R A x}}
$$

$V_{A}$ - wind speed,

$\gamma_{A}-$ geographic wind direction, $\left(\gamma_{A}=0^{\circ}-\right.$ north wind, $\gamma_{A}=90^{\circ}-$ east wind $)$,

$V$ - speed of the ship,

$\psi$ - geographical course of the ship.

In the equations (8) and in Fig. 2, it was assumed that if the ship is going upwind, the wind is an additional resistance, if the wind is from the stern of the ship, then the effect of wind reduces the total resistance.

\section{Wave influence on the ship}

The average impact forces of an irregular wave (mean wave drift force) on a sailing vessel can be calculated from the formulas:

$$
\begin{aligned}
& R_{W x}=2 \rho_{w} g \frac{B^{2}}{L} \int_{0}^{\infty} C_{W x}\left(\frac{\omega}{\beta_{W}}, V\right) S_{\zeta \zeta}(\omega) \mathrm{d} \omega, \\
& R_{W y}=2 \rho_{w} g \frac{B^{2}}{L} \int_{0}^{\infty} C_{W y}\left(\omega / \beta_{W}, V\right) S_{\zeta \zeta}(\omega) \mathrm{d} \omega, \\
& M_{W z}=2 \rho_{w} g B^{2} \int_{0}^{\infty} C_{W m}\left(\omega / \beta_{W}, V\right) S_{\zeta \zeta}(\omega) \mathrm{d} \omega,
\end{aligned}
$$

where:

$\rho_{w}$ - water density,

$g$ - acceleration to gravity,

$B$ - ship breadth,

$C_{W x}, C_{W y}, C_{W m}\left(\omega / \beta_{W}, V\right)$ - coefficients of regular-wave-generated drift force depending on the wave direction relative to the ship $\beta_{W}$, and the ship speed $V$,

$\omega$ - regular wave frequency,

$\beta_{W}$ - wave direction relative to the ship (Fig. 2), $\beta_{W}=0^{\circ}$ wave reaching the stern of the ship (incoming wave), $\beta_{W}=90^{\circ}$ side wave (on LB),

$$
\beta_{W}=\mu-\psi+180^{\circ},
$$

$\mu$-geographical wave direction $\left(\mu=0^{\circ}\right.$ - north wave, $\mu=90^{\circ}$ - east wave),

$S_{\zeta \zeta}(\omega)$ - wave energy spectral density function (dependent on the significant wave height $H_{S}$ and mean period wave $T_{1}$ ).

\section{Additional the ship resistance due to passive rudder}

When the ship is sailing on the waves, especially when the ship is wind and wave obliquely, lateral forces and moments are created that force the course of the ship to change and a drift is created. To maintain a constant course, the rudder blade should be tilted (Fig. 3), which creates additional resistance $R_{R x}$.

The forces on the rudder blade are the equations:

$$
\begin{gathered}
R_{R x}=\left|F_{N} \sin \delta_{R}\right|, \\
R_{R y}=a_{y} F_{N} \cos \delta_{R}, \\
M_{R z}=a_{y} F_{N} \cos \delta_{R},
\end{gathered}
$$

where: 
$\delta_{R}$ - rudder angle (Fig. 3 - rudder angle at portside $\delta_{R}>0$, rudder angle at starboard $\left.\delta_{R}<0\right)$,

$a_{y}$ - coefficient of hull influence on the rudder force $R_{R y}$,

$a_{z}$ - coefficient of hull influence on the rudder moment $M_{R z}$ on the rudder,

$$
a_{z}=a_{y} x_{R}
$$

$x_{R}$ - distance of rudder axis measured from the ship mass centre $G\left(x_{R}<0\right)$,

$F_{N}$ - rudder normal force (Fig. 3),

$$
F_{N}=\frac{1}{2} \rho_{W} \frac{6,13 \lambda}{\lambda+2,25} A_{R} V_{R}^{2} \sin \alpha_{R}
$$

$\lambda$ - rudder aspect ratio,

$A_{R}$ - rudder surface area,

$V_{R}$ - water inflow velocity to rudder (Fig. 3),

$\alpha_{R}$ - effective rudder angle of attack (Fig. 3).

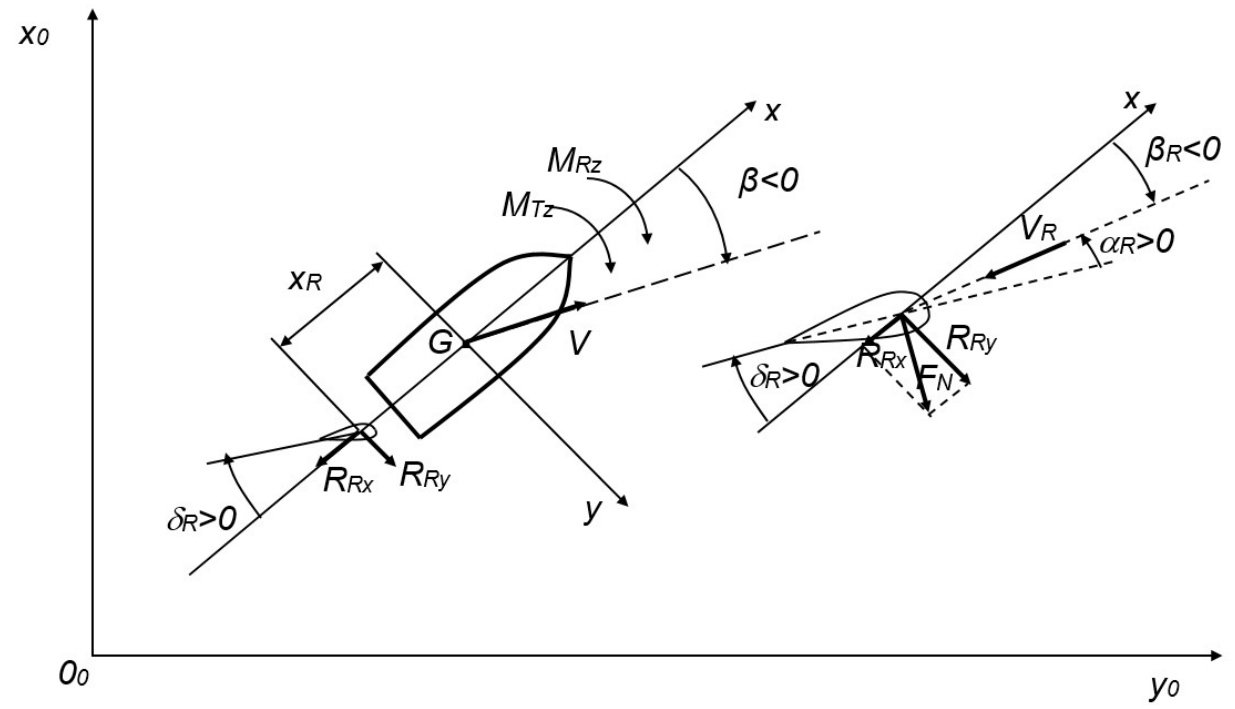

Fig. 3. Forces and moment on the rudder blade, rudder angle and angle of attack

As a result of the reactive rudder deflection, the moment $M_{R z}$ is created from the force $R_{R y}$ and to maintain the course of the ship, the moment on the rudder should have such a value as to balance the resultant torque from wind, wave and resistance (including the current) at the drift angle:

$$
M_{T z}=-M_{R z},
$$

where $M_{T}$ is the total moment from the marine environment (wind, wave and from the current or water when the ship is flying with drift angle):

$$
M_{T Z}=M_{A z}+M_{W z}+M_{C V Z} .
$$

Therefore, the size of the rudder angle $\delta_{R}$ will be calculated from equation (18) for the current external moments acting on the ship from the marine environment (19). Knowing the current value of $\delta_{R}$ from the first equation (15), additional resistance will be calculated from the reactive rudder in given weather conditions.

\section{SHIP PROPULSION}

In order for a ship to reach a certain speed $V$, the thrust propeller $T$ must balance the total resistance of the ship $R_{T}$ to the weather conditions:

$$
T=\frac{R_{T}}{1-t},
$$

where $t$ is the suction coefficient (the value of the suction coefficient may depend on the vessel speed $t(V)$ ).

On the working screw, the torque $Q$ is created: 


$$
Q=K_{Q} \rho_{w} D_{p}^{5} n_{p}^{2}
$$

$n_{p}$ - rotation speed of the propeller.

Between the torque on the screw (21) and the power supplied to the screw cone $\left(P_{D}\right)$ is the following relationship:

$$
P_{D}=Q \cdot 2 \pi n_{p},
$$

between power $P_{D}$ and the power of the propulsion engine motor $N$ :

$$
N=\frac{P_{D}}{\eta_{G} \cdot \eta_{S} \cdot \eta_{R T}}
$$

where:

$\eta_{G}$ - gearbox efficiency, if used,

$\eta_{S}$ - the efficiency of the shaft line,

$\eta_{R T}$ - rotational "efficiency" (rotational "efficiency" may vary depending on the speed of the $\left.\operatorname{ship} \eta_{R T}(V)\right)$.

\section{THE SPEED OF THE SHIP ON THE OCEAN ROUTE IN REAL WEATHER CONDITIONS}

The movement of the ship along the ocean route has been described by the arrangement of three non-linear equations:

$$
\begin{gathered}
R_{T}=R_{C V x}+R_{A x}+R_{W x}+R_{R x}, \\
R_{A y}(V)+R_{W x}(V)+R_{y}(V, \beta)+R_{R x}\left(V, \beta, \delta_{R}\right)=0, \\
M_{A z}(V)+M_{W z}(V)+M_{z}(V, \beta)+M_{R z}\left(V, \beta, \delta_{R}\right)=0,
\end{gathered}
$$

in which the individual components of forces $R_{x}$ and $R_{y}$ and moments $M_{z}$ are dependent on:

- search speed $V$,

- weather parameters (wind, current and wave),

- ship's course $\psi$, drift angle $\beta$ and rudder angle $\delta_{R}$,

- geometric parameters characterizing of the ship.

Then, the speed of the ship is sought, at which the total resistance of the ship will be balanced by the thrust propeller, and the moment on the propeller will in the field defined by the characteristics of the engine. The search speed of the ship in given weather conditions is calculated from the system of two successive nonlinear equations:

$$
\begin{gathered}
{\left[\left(A_{0}+A_{1} \cdot J+A_{2} \cdot J^{2}+A_{3} \cdot J^{3}\right)+\Delta K_{T}\right] \rho_{w} D_{p}^{4} n_{p}^{2} \beta_{T}-\frac{R_{T}}{1-t}=0,} \\
{\left[\left(B_{0}+B_{1} \cdot J+B_{2} \cdot J^{2}+B_{3} \cdot J^{3}\right)-\Delta K_{Q}\right]-\frac{N \cdot \eta_{G} \cdot \eta_{S} \cdot \eta_{R T}}{2 \pi \rho_{w} D_{p}^{5} n_{p}^{3}}=0,}
\end{gathered}
$$

where:

$J$ - advance coefficient,

$$
J=\frac{V\left[1-w_{T}(V)\right]}{D_{p} n_{p}}=0,
$$

$A_{0}, A_{1}, A_{2}, A_{3}, B_{0}, B_{1}, B_{2}, B_{3}, \Delta K_{T}, \Delta K_{Q}$ - parameters specifying the characteristics of the propeller, e.g. (Oosterveld and van Oossanen, 1975),

$D_{p}, n_{p}$ - diameter and revolutions of the propeller,

$N$ - power of the propulsion engine,

$\beta_{T}$ - correction factor taking into account the thrust drop at the ascent of the screw on the wave (Minsaas et al., 1986),

$\eta_{G}, \eta_{S}, \eta_{R T}$ - respectively: transmission efficiency (if applicable), shaft line efficiency, rotational efficiency of the propeller.

Systems of equations (24) and (25) are solved in an iterative manner so that for the calculated speed $V$, (Szelangiewicz and Żelazny, 2007), the working point of the engine lies in the field of work. When searching for speed $V$, you can use various additional criteria, eg minimum fuel consumption, maximum speed in given weather conditions (Białostocki and Konovessis, 2016). 


\section{MODEL VERIFICATION AND CONCLUSIONS}

1. The presented mathematical model of ship speed forecasting in real weather conditions has been verified on the basis of experimental model tests. An example of the verification of resistance coefficients on calm water, taking into account the angle of drift (for the drift angle range that occurs during the voyage of a ship along the ocean route) is shown in Figure 4.
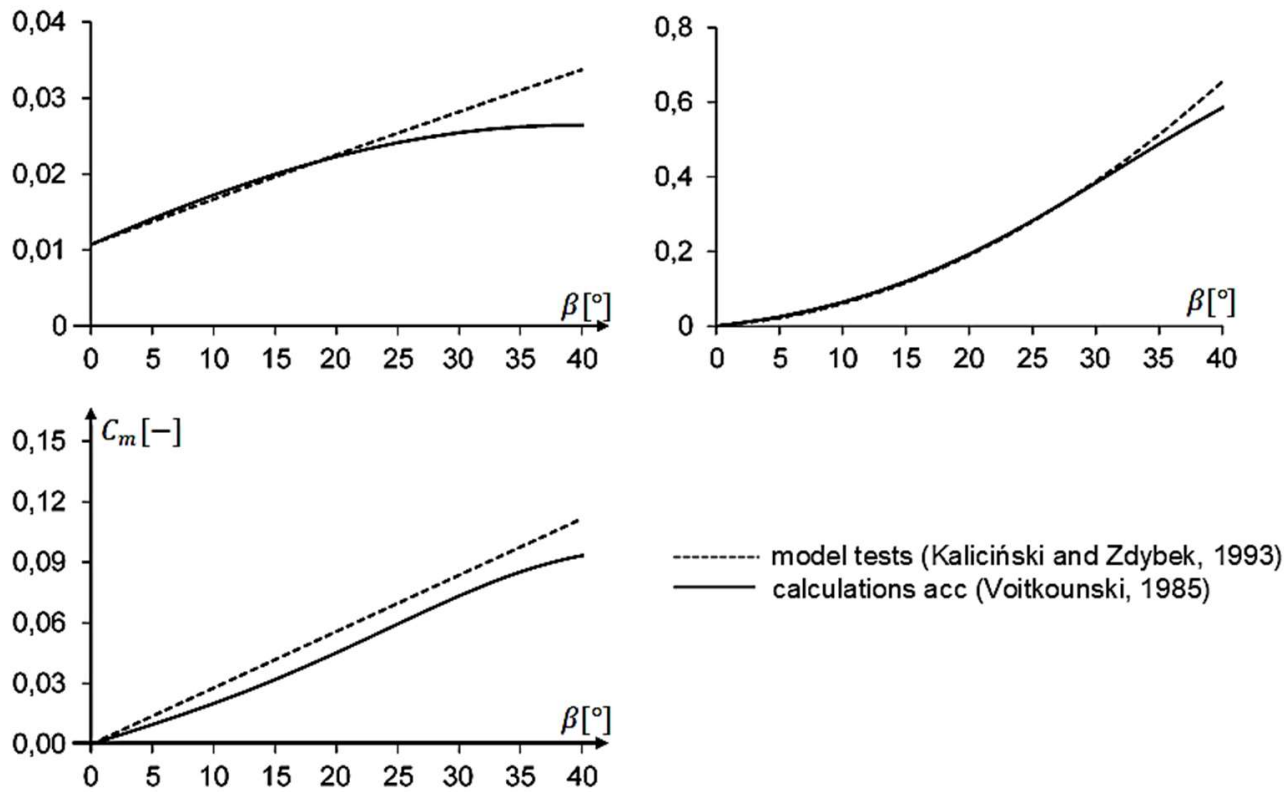

Fig. 4. Ship resistance coefficients of a container ship $(L=140.14 \mathrm{~m}, B=22.3 \mathrm{~m}, T=8.25 \mathrm{~m}$, $\nabla=17290 \mathrm{~m}^{3}$ ) for speed $V=8.4 \mathrm{~m} / \mathrm{s}$ during movement with drift angle, calculations according to (Voitkounski, 1985)

2. The presented model of ship the speed forecasting requires knowledge of ship's geometric parameters and propulsion parameters (engine and propeller). For operated ships these data are available, and the effect of using this model is a more accurate forecast of the speed of the ship than in the case of using very simplified mathematical models.

3. The next article will include the ship speed calculations in real weather conditions obtained from the presented model and compared with the results from the simplified models.

\section{REFERENCES}

Białostocki, N. and Konovessis, D. (2016). On the estimation of ship fuel consumption and speed curve: A statistical approach. Journal of Ocean Engonieering and Science, 7(2), pp. 157-166.

Bon Voyage System (BVS) voyage optimization software. (2016). Applied Weather Technologies (AWT), Kifer Court. Sunnyvale CA 94086. V. 7.1.

Kaliciński, J. and Zdybek. T. (1993). Prognozowanie charakterystyk hydrodynamicznych podwodzi statków typu RO-RO. X Sympozjum Hydromechaniki Okrętowej, Centrum Techniki Okrętowej, Gdańsk, Tom II, pp. 113-128

Minsaas, K.J., Thon, H.J. and Kauczyński, W. (1986). Influence of Ocean Environment on Thruster Performance. In: Proc. of. Int. Symp. Propeller and Cavitation, Supplementary volume, Shanghai: The Editorial Office of Shipbuilding of China, pp. 124-142.

Oosterveld, M.W.C. and van Oossanen, P. (1975). Futher Computer-Analyzed Data for the Wageningen B-Screw Series. International Shipbuilding Progress, 22(251).

Program SPOS Fleet Management. (2009). Meteo Consult BV, The Netherlands, V. 7.0.0.1.

Szelangiewicz, T. and Żelazny, K. (2007). Calculation of mean long-term service speed of transport ship. Polish Maritime Research, 1, pp. 28-32.

Szymanski, M. and Wisniewski, B. (2016). Application of Bon Voyage 7.0 (AWT) to programming of an ocean route of post-Panamax container vessel in transpacific voyage Seattle - Pusan 26.08.2015, 1600UTC-05.09.2015, 2100UTC. Scientific Journals of the 
Maritime University Of Szczecin. Zeszyty Naukowe Akademii Morskiej w Szczecinie. 48(120), pp. 182-186.

Voitkounski, Y.T. (1985). Ship Theory Handbook, Leningrad: Sudostroenie.

Wiśniewski, B. (1991). Problemy wyboru drogi morskiej. Gdańsk: Wydawnictwo Morskie.

Wiśniewski, B., Wielgosz, M. and Korwin-Piotrowski, T. (2012). Procedury zintegrowanego planowania i programowana tras oceanicznych statków z wykorzystaniem systemu SPOS. Szczecin: Akademia Morska w Szczecinie.

Date of submission of the article to the Editor: 02/2018

Date of acceptance of the article by the Editor: 05/2018 